\title{
Presentación de Andrew Samuels
}

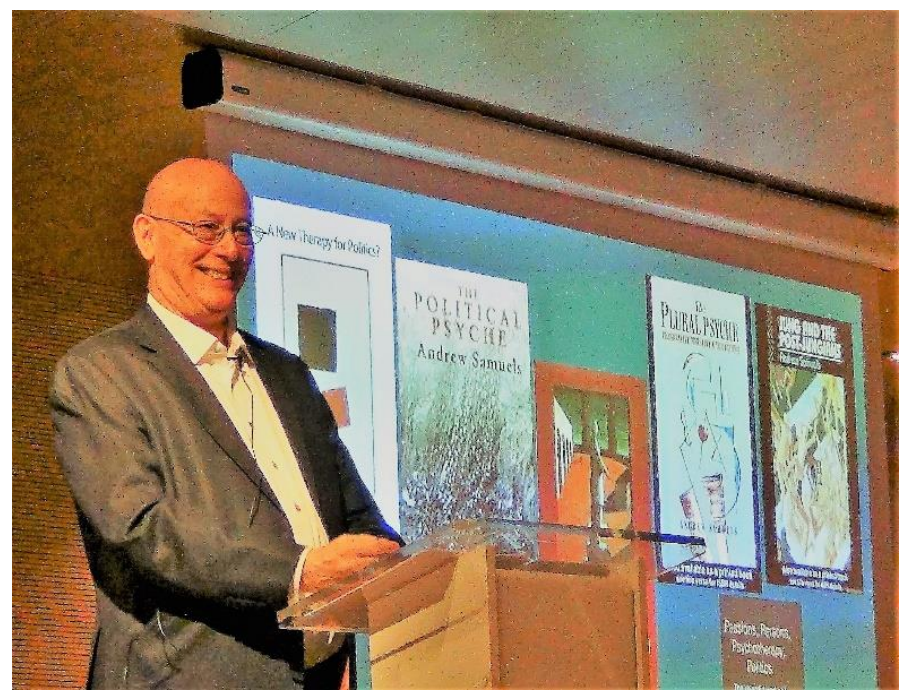

Realizada por PILAR QUIROGA MÉNDEZ ${ }^{1,2}$

Andrew Samuels es un autor conocido internacionalmente por una obra escrita en 1985 llamada Jung y los postjungianos, recientemente traducida al español con un magnífico prólogo de E. Galán (Samuels, 2015). Esta obra fue y es muy importante para la psicología analítica porque ofrece una clasificación que ordena las aportaciones de las diversas escuelas y autores posteriores a Jung. La psicología analítica, aunque en España sea una corriente muy minoritaria, tiene en todo el mundo cientos de sociedades y miles de analistas. La propuesta de Samuels para la clasificación de los autores posteriores a Jung definió tres escuelas: clásica, evolutiva y arquetipal, que posteriormente convirtió en cuatro. Pero lo más importante de este libro fue su capacidad para ofrecer una visión pluralista dentro de la psicología analítica. Esa visión permitió dar un lugar a todos, ser suficientemente flexible y abierta como para fortalecer la disciplina, abarcar superposiciones y permitir un marco de respeto y acceso relativamente rápido a los temas candentes de la psicología analítica. Esta categorización hizo posible que se respetaran las diferencias entre jungianos, atendiendo al mismo tiempo a lo que tienen en común. Por todo ello podemos considerarla un éxito, un gran éxito si recordamos como suelen resolverse las divergencias en las escuelas de psicoanálisis y en la vida en general.

${ }^{1}$ Quiroga Méndez, P. (2018). Presentación de Andrew Samuels. Clínica e Investigación Relacional, 12 (1): 29-33. [ISSN 1988-2939] [Recuperado de www.ceir.info ] DOI: 10.21110/19882939.2018.120102 ${ }^{2}$ Psicóloga y Psicoterapeuta. Profesora de la Universidad Pontificia de Salamanca. Miembro del Instituto de Psicoterapia Relacional.

CeIR Vol. 12 (1) - Febrero 2018 ISSN 1988-2939 - www.ceir.info

@ ( Derechos reservados/Copyright de Clínica e investigación Relacional y los autores. Prohibida la reproducción total o parcial sin autorización expresa. Este material es para uso científico y profesional exclusivamente y puede contener información clínica sensible. Los editores no se responsabilizan de los contenidos de los autores. Dirigir las consultas sobre derechos y autorizaciones a ceir@psicoterapiarelacional.es 
Podemos leer en español dos textos más de A. Samuels: El padre (Samuels, 2016), traducido a nuestro idioma también treinta años después, y una introducción muy recomendable de menos de 20 páginas a un libro editado por Polly Young-Eisendrath y Dawson llamado: Introducción a Jung. Sobre este capítulo quiero resaltar la referencia a Jung como precursor de la mayoría de los desarrollos más recientes del psicoanálisis. Es un hecho que Jung es uno de los autores de la psicología profunda menos citado, y lo es también que las aportaciones de este autor están en el origen de muchos conceptos hoy comúnmente utilizados en psicología profunda. Podemos señalar la concepción del inconsciente, la preeminencia de la figura materna, los aspectos creativos de la psique, la capacidad de autorregulación del sistema psíquico, el valor del síntoma, los arquetipos, la noción de totalidad o el concepto del self. Todos estos aspectos han ido apareciendo en diferentes psicoterapias sin olvidar, para este contexto relacional en el que nos encontramos, la forma de percibir la interacción entre el paciente y el terapeuta como mutuamente transformadora para ambos. En este sentido destaca la alianza terapéutica entretejida con aspectos contratransferenciales configurando un espacio intersubjetivo, y todo ello teniendo en cuenta que el modelo alquímico utilizado por Jung es de hecho intersubjetivo, como Samuels señala. En esta área las ideas de Jung tienen puntos en común con diversas concepciones de Atwood, Stolorow, Greenson, Kohut, Mitchell, y Miller.

Hay que volver al éxito de Jung y los posjungianos, la clasificación de las escuelas de psicología analítica porque la clave, el encuadre y el éxito de Samuels y sus intervenciones, radica precisamente lo que habíamos señalado como "una visión pluralista". Esta visión la aplica primariamente a la psique personal y posteriormente a las diferentes escuelas de psicoterapia, para finalmente utilizarla como una interpretación de la sociedad y de la política. Todo esto es tratado, en una de sus obras más importantes: The Plural Psyche (1989). En su introducción Samuels señala que el pluralismo es una actitud hacia el conflicto, actitud que intenta reconciliar las diferencias sin imponer una resolución falsa sobre ellas, o perder de vista el valor único de cada posición. Asimismo, también puede presentarse el pluralismo como una ideología, que busca mantener la unidad y la diversidad en equilibrio; diferenciándose de otros términos como eclecticismo", síntesis", "paralelismo o "perspectivismo".

Aunque el pluralismo aparezca como una estrategia integradora, Samuels va más allá señalando que no trata simplemente de presentarl como un estado u objetivo deseable para la psicología, sino que sugiere que se comience a utilizar la idea del pluralismo como una promesa de que la diversidad no lleva necesariamente al conflicto cismático. Este instrumento también nos dirá cuándo una división se ha convertido en inevitable o incluso en deseable. El pluralismo podría funcionar como un instrumento para revisar el "mosaico 
de la psique", o el de la psicología profunda, y ayudarnos a realizar reparaciones cuando sea necesario. Así la perspectiva plural no será solamente un objetivo, sino también un criterio. El pluralismo inequívocamente trata de las relaciones entre lo Uno y lo Múltiple, hasta terminar afirmando que, en esa lucha, el Uno tiene que aceptar que es solo una posibilidad entre muchas.

En el nivel personal, nos enfrentamos a la tarea plural de reconciliar nuestras muchas voces internas e imágenes de nosotros mismos con la necesidad de sentirnos integrados y de hablar con una sola voz. En este sentido hay que recordar que la psicología jungiana parte de una visión plural de lo psíquico, por lo cual esta perspectiva no le es en absoluto ajena. La psicología analítica define la psicología individual como configurada por diferentes subpersonalidades, partes escindidas en colaboración y en conflicto. Una psique politeísta como Jung la describe en su psicología de los complejos. La psicología concibe la existencia de entidades vivientes encerradas en ella, a veces personas, pero a menudo daimones, animales o dioses. Incluso el freudiano clásico más científico hablará de que el ego es fuerte o débil y de las relaciones entre el ego, el ello y el superyó como si fueran tres personajes. La creación de la psicología no parece posible sin ese tipo de personificación implícita. Jung fue el máximo exponente de esta corriente, toda su psicología toma la forma de una animación de personajes internos. Una metáfora política, como el pluralismo, ayuda a evaluar las tensiones y oscilaciones dentro de la psique de todos sus personajes, a los que Samuels pone voz: ¿Qué derechos tiene cada parte? ¿cuáles están en franca competencia? ¿hay una élite con privilegios especiales?.

Un enfoque pluralista ilumina también los problemas de confrontación de las diversas escuelas de psicología profunda. El psicoanálisis está intensamente dividido en escuelas y aunque muchos analistas y terapeutas están comprometidos con el diálogo, no se puede dejar de ver la falta de una actitud general de tolerancia. Samuels señala que esto debe a la apasionada devoción de los psicoanalistas por su propio enfoque, y encuentra necesario encontrar un programa que pueda combinar la pasión y la tolerancia en la psicología profunda. El pluralismo señala, sería la actitud que puede mantener la tensión entre tendencias hacia la unidad, y entre las demandas hacia la diversidad, situándose dentro de una multiplicidad de puntos válidos procedentes de diferentes enfoques. Moviéndose siempre entre "lo uno y lo múltiple" aparecen otras valiosas afirmaciones en las que este autor asegura que ningún tipo de enfoque es a priori mejor, salvo como una cuestión de "preferencia personal y lealtad". Entre las diferentes escuelas, la posición de Samuels va más allá del eclecticismo afirmando que, para convertirse verdaderamente en "sí mismo" el psicólogo profundo no puede pertenecer solo a una escuela. Existe una interdependencia con todas las formas posibles de divergencia y convergencia en psicoanálisis. Las diferentes 
escuelas de psicología profunda simbolizan líneas del "ser profesional" dentro de un único analista, de modo que la exploración de la diferencia ideológica se convierte en una expedición al interior, una cuestión de individuación.

En el capítulo 11 de esta obra Samuels destaca la fragmentación y la disputa dentro de la psicología profunda, que aparece cuando los analistas individuales y los grupos de analistas luchan por la aceptación general de esa particular "confesión personal" en la que han realizado su principal inversión. Esto parece ser lo opuesto al pluralismo, sin embargo, usando la idea de la compensación inconsciente, que es un término netamente junguiano, es posible ver la psicología profunda como una lucha hacia el pluralismo. Lo que parece una fuga del pluralismo también puede ser un anhelo por su plenitud y una aceptación en algún nivel de un destino pluralista para la psicología profunda. La agresión, tan característica de los debates entre analistas, a menudo contiene las necesidades más profundas de contacto, diálogo, reproducción y afirmación. Al competir con otros, podemos llegar a conocernos a nosotros mismos y nuestras ideas mejor y más profundamente. Un ejemplo específico de la importancia del Otro reflejo, cuya presencia brilla en tantas psicologías como las de Jung, Winnicott, Neumann, Lacan, Kohut. Este Otro es un otro creativo y necesita nutrición para que no aparezca el oponente que es el receptáculo del prejuicio y la proyección de fantasías de superioridad, señalará Samuels. La psicología de la profundidad es un movimiento que históricamente se ha mostrado muy capaz de resistir los choques y las divisiones, pudiendo crear nuevas hipótesis a partir de ellos.

La psicología profunda sigue deseosa de entrar en un estado plural, pero carece de la metodología necesaria, afirma Samuels. Es posible que todos seamos pluralistas, pero las diversas formas de omnipotencia e idealización nos alientan a negarlo. Hemos de tener en cuenta, señala el autor, que la tendencia hacia la multiplicidad y a la diversidad es tan fuerte y creativa, como la búsqueda de la unidad o la lucha por la hegemonía.

The Plural Psique fue la primera obra sobre política de Samuels, a la que se unieron posteriormente The Political Psyche (1993) y The Politics on the Couch (2001), configurando una trilogía dedicada a pensar la política desde la psicología, y a indagar en los aspectos políticos de la psicoterapia. A estas obras se añade la última: A New Therapy for Politics (2015). Samuels señala cómo nuestro mundo actual aparece enormemente fragmentado y balcanizado, por lo que nunca ha sido más difícil hacer un análisis político que ahora. El autor alerta sobre la fragilidad y la desunión de nuestra cultura que provoca una peligrosa reacción de totalidad, o de totalitarismos, ante la cual la noción de pluralismo es la única reacción posible. En su aplicación social, el pluralismo político sugiere que el fomento de la negociación competitiva entre intereses en conflicto produce resultados creativos en lugar

() Derechos reservados/Copyright de Clínica e investigación Relacional y los autores. Prohibida la reproducción total o parcial sin autorización expresa. Este material es para uso científico y profesional exclusivamente y puede contener información clínica sensible. Los editores no se responsabilizan de los contenidos de los autores. Dirigir las consultas sobre derechos y autorizaciones a ceir@psicoterapiarelacional.es 
de destructivos. En su última obra señala que los objetivos políticos de la moderna democracia son similares a los objetivos psicológicos de la moderna psicoterapia, en ambos existe una lucha entre la conciencia, la liberación y la alteridad por un lado, y la supresión represión y creencias omnipotentes por otro. Al final los problemas sociales se convierten en la psicopatología del mundo. Sigue vigente en esta última obra el esquema del pluralismo, no como eclecticismo o síntesis, sino como una herramienta contra la escisión. Se trata de realizar una aproximación al conflicto (ahora conflicto social o político) que intente reconciliar diferencias sin imponer una falsa síntesis y sin perder de vista el particular valor y verdad de cada elemento en conflicto. Además, introduce la política en la sesión terapéutica, buscando el mito político de la persona, al mismo tiempo que incluye el psicoanálisis dentro de ámbito de la política como una más de las disciplinas que pueden ayudar a su óptimo desarrollo.

Samuels se define a sí mismo como un psicoterapeuta, un académico y un activista político. Este activismo aparece en palabras valientes desenfadadas, desmitificadoras y en una feroz autocrítica, un ejemplo es la afirmación de que los terapeutas no pueden influir en el mundo porque siempre quieren tener razón, quieren reducirlo todo a lo que ellos saben, se han confabulado con regimenes opresivos y ellos mismos están divididos. (Samuels, 2015). Samuels es definido desde su CV como analista de la Sociedad de Psicología Analítica de Londres, miembro activo de la Asociación Internacional de Psicología Analítica y asesor científico de la Academia Americana de Psicoanálisis. Es conocido internacionalmente como un comentarista influyente sobre temas políticos y sociales desde el punto de vista del "pensamiento terapéutico" Ha trabajado como consultor político con políticos, organizaciones políticas, y grupos de activistas en Europa, EE. UU., Brasil, Israel, Japón, Rusia y Sudáfrica. Clínicamente, ha desarrollado una combinación única de enfoques junguianos y postjungianos, psicoanalíticos relacionales y humanísticos.

Junto con R. Papadopoulos estuvo entre los primeros profesores en la universidad de Psicología Analítica del mundo. En 2006, fue elegido como uno de los primeros seis miembros honorarios del Consejo de Psicoterapia del Reino Unido (UKCP). En 2009, fue elegido presidente de este consejo. Es Profesor de Psicología Analítica en Essex, Profesor Visitante de Estudios Psicoanalíticos en Goldsmiths (Universidad de Londres), Profesor Honorario de Psicología y Estudios Terapéuticos en Roehampton, y Profesor Adjunto Visitante en el Programa Posdoctoral de Psicoterapia y Psicoanálisis de la Universidad de Nueva York. expresa. Este material es para uso científico y profesional exclusivamente y puede contener información clínica sensible. Los editores no se responsabilizan de los contenidos de los autores. Dirigir las consultas sobre derechos y autorizaciones a ceir@psicoterapiarelacional.es 